\title{
Correction to: Multimodality Treatment Improves Locoregional Control, Progression-Free and Overall Survival in Patients with Anaplastic Thyroid Cancer: A Retrospective Cohort Study Comparing Oncological Outcomes and Morbidity between Multimodality Treatment and Limited Treatment
}

Pascal K. C. Jonker, MD ${ }^{1,2}$, John Turchini, BMedSc, MBBS, FRCPA ${ }^{3,4,5}$, Schelto Kruijff, MD, PhD ${ }^{2}$, Jia Feng Lin, BSc ${ }^{1,2}$, Anthony J. Gill, MD, FRCPA ${ }^{3,6,7}$, Thomas Eade, MD $^{8}$, Ahmad Aniss, MSc, PhD ${ }^{1}$, Roderick Clifton-Bligh, MD, PhD ${ }^{3,9}$, Diana Learoyd, MBBS, FRACP, PhD ${ }^{3,9}$, Bruce Robinson, MD, MSc, FRACP $^{3,9}$, Venessa Tsang, MBBS, BSc(Med), FRACP, PhD ${ }^{3,9}$, Anthony Glover, MBBS, FRACS, PhD ${ }^{1,3,10,11}$, Stanley Sidhu, MD, FRACS, PhD ${ }^{1,3}$, and Mark Sywak, MBBS, FRACS, MMed Sci ${ }^{1,3,12}$

\footnotetext{
${ }^{1}$ University of Sydney Endocrine Surgical Unit, Royal North Shore Hospital, Northern Sydney Local Health District, St Leonards, Australia; ${ }^{2}$ Department of Surgery, University Medical Center Groningen, University of Groningen, Groningen, The Netherlands; ${ }^{3}$ Northern Clinical School, Sydney Medical School, Faculty of Medicine and Health, University of Sydney, Sydney, NSW, Australia; ${ }^{4}$ Douglass Hanly Moir Pathology, Macquarie Park, NSW, Australia; ${ }^{5}$ Discipline of Pathology, MQ Health, Macquarie University, Macquarie Park, NSW, Australia; ${ }^{6}$ NSW Health Pathology Department of Anatomical Pathology, Royal North Shore Hospital, Northern Sydney Local Health District, St Leonards, NSW, Australia; ${ }^{7}$ Cancer Diagnsosis and Pathology Group, Kolling Institute of Medical Research, Royal North Shore Hospital, Northern Sydney Local Health District, St Leonards, NSW, Australia; ${ }^{8}$ Department of Radiation Oncology, Royal North Shore Hospital, Northern Sydney Local Health District, St Leonards, NSW, Australia; ${ }^{9}$ Department of Endocrinology, Royal North Shore Hospital, Northern Sydney Local Health District, St Leonards, Australia; ${ }^{10}$ Endocrine Cancer Program, Cancer Theme, The Kinghorn Cancer Centre, Garvan Institute of Medical Research, Sydney, NSW, Australia; ${ }^{11}$ St. Vincent's Clinical School, Faculty of Medicine, University of New South Wales Sydney, Sydney, NSW, Australia;

${ }^{12}$ University of Sydney Endocrine Surgery Unit, AMA House, St Leonards, NSW, Australia
}

CORRECTION TO: ANN SURG ONCOL https://doi.org/10.1245/s10434-021-10146-3

The original online version of this article has been revised. Ahmad Aniss's family name was corrected.
Publisher's Note Springer Nature remains neutral with regard to jurisdictional claims in published maps and institutional affiliations.

The original article can be found online at https://doi.org/10.1245/ s10434-021-10146-3.

(C) Society of Surgical Oncology 2021

Published Online: 19 July 2021

M. Sywak, MBBS, FRACS, MMed Sci

e-mail: marksywak@nebsc.com.au 